\title{
PONTO DE COLHEITA IDEAL DE MANGAS 'TOMMY ATKINS’ DESTINADAS AO MERCADO EUROPEU ${ }^{1}$
}

\author{
PATRÍCIA LÍGIA DANTAS DE MORAIS ${ }^{2}$, HELOISA ALMEIDA CUNHA FILGUEIRAS ${ }^{3}$, JOÃO LICÍNIO NUNES \\ DE PINHO ${ }^{4}$ E RICARDO ELESBÃO ALVES ${ }^{5}$
}

\begin{abstract}
RESUMO - Este trabalho foi desenvolvido em um pomar comercial do Pólo Agrícola Mossoró-Assu, localizado no município de Assu-RN. Teve como objetivo caracterizar e determinar o melhor estádio de maturação para a colheita de mangas 'Tommy Atkins' destinadas ao mercado Europeu. Os frutos foram marcados e avaliados aos 82 (E1), 89 (E2), 96 (E3) e 103 (E4) dias após a floração plena (DFP) e no estádio de colheita comercial (EC)., As avaliações foram feitas por ocasião da colheita e após 21 dias de armazenamento refrigerado $\left(13 \pm 1^{\circ} \mathrm{Ce} 99 \% \mathrm{UR}\right)$. As variáveis analisadas foram cor da casca e da polpa do fruto, perda de massa, firmeza, sólidos solúveis totais (SST), acidez total titulável (ATT), relação SST/ATT, açúcares solúveis totais (AST), amido e atividade respiratória. Observou-se que, os picos climatéricos ocorreram aos 10 dias após a colheita nos frutos colhidos no estádio E2 e aos 7 dias nos colhidos nos estádios E3 e EC. Os frutos colhidos nos estádios E2, E3, E4 e EC amadureceram normalmente após 21 dias de armazenamento refrigerado. Sendo que os colhidos nos estádios E3 e EC se apresentaram muito semelhantes e alcançaram melhor qualidade, indicando que a colheita pode ser realizada nesses estádios, e que o período de 96 DFP pode ser considerado como mais um indicador do ponto de colheita.
\end{abstract}

Termos para indexação: Mangífera indica L., ponto de colheita, amadurecimento

\section{HARVESTING MATURITY OF MANGOES 'TOMMY ATKINS’ TO THEFOR EUROPEAN MARKET}

ABSTRACT - The experiment was carried out with the objectives of to characterize thee it's harvesting maturity of 'Tommy Atkins' mangoes. The fruits were marked and evaluated on at 82 (E1), 89 (E2), 96 (E3) e and 103 (E4) days after flowering full bloom (DAF) and at the commercial harvesting stage (CSEC). Evaluations were carried out, on the day of the harvest and after 21 days of under refrigerated storage ( $13 \pm 1{ }^{\circ} \mathrm{C} \mathrm{e}$ and $99 \%$ R.H.). The characteristics evaluated were skin and pulp color, weight loss, firmness, total soluble solids (TSS), total titrable acidity (TTA), TSS/TTA ratio, total soluble sugar and starch contents, and respiratory activity. It was concluded that, climacteric respiratory peaks happened were noticed after 10 days after harvest in mangoes harvested at stage E2 and after 7 days forin those harvested at stages E3 and CSEC. Fruits harvested at E2, E3, E4 and CS EC stages, ripened normally after 21 days of in refrigerated storage. Mangoes harvested at E3 and CS EC stages had similar behavior and showbehaved similarly and reached eating the high quality, indicating that harvest should can be done at these stages, and that 96 DAF should be considered as another harvest maturity index.

Index Terms: Mangífera indica L., maturity index, ripening

\section{INTRODUÇÃO}

No Nordeste brasileiro, a manga é cultivada em todos os estados, tendo-se observado, nos últimos anos, significativo aumento nas exportações, notadamente da cultivar Tommy Atkins (Leite et al., 1998). O mercado europeu, segundo projeções da FAO (2001), é o mais promissor para a manga brasileira. Atualmente, o Brasil é um dos principais fornecedores de manga para o Reino Unido, sendo estas exportações realizadas diretamente ou via Holanda (Pimentel et al., 2000).

Por por conseguir produzi-la em um período de pouca oferta, a manga é uma das frutas tropicais brasileiras que alcança melhor preço no mercado internacional. Porém, essa situação pode ser modificada, já que outros países também estão buscando ampliar seus períodos de produção. Para superar este aspecto e estimular o consumo da manga nos países industrializados, o Brasil precisa tomar medidas que assegurem a qualidade elevada, uniforme e constante da fruta que chega ao consumidor (GTZ, 1992; Pimentel et al., 2000).

A qualidade da manga para consumo e sua capacidade de conservação pós-colheita dependem, principalmente, do grau estádio de desenvolvimento do fruto no momento da colheita. Assim, frutas que não completaram a fase de desenvolvimento fisiológico no campo, podem conservar-se por um longo período de tempo, porém jamais alcançarão a qualidade ideal para o consumo (Guarinoni, 2000). Segundo Botton (1992), o estádio inadequado de maturação fisiológica é uma das maiores causas de perdas, ou baixa qualidade de mangas brasileiras que chegam à Europa por via marítima.

O objetivo deste trabalho foi caracterizar e determinar o melhor estádio de maturação para colheita, garantindo a qualidade da manga 'Tommy Atkins' destinada ao mercado europeu, produzida sob condições de irrigação no Pólo Agrícola Mossoró-Assu (RN).

\section{MATERIAL EMÉTODOS}

O experimento foi realizado em um pomar comercial localizado no Pólo Agrícola Mossoró-Assu, da Empresa FRUNORTE Ltda, no município de AssuAssu-RN, durante o período de 12 de março a 13 de abril de 2000. No pomar utilizado, foram realizadas 6 induções florais, adubações de fundação com gesso e foliar com micronutrientes, aplicações de inseticidas e fungicidas, e todas as práticas culturais usuais na fazenda. Foram selecionadas cerca de 200 árvores plantas decom 8 anos de idade, nestas nas quais foram marcadas 200 panículas, 32 dias após o início da floração plena (DFP). Os frutos foram colhidos com idades de 82 (E1), 89 (E2), 96 (E3) e 103 (E4) dias após iniciada a floração plena, e no estádio comercial (EC), de acordo com os indicadores externos do ponto de colheita para a exportação (aproximadamente 90 DFP), utilizados pelos técnicos da Empresa FRUNORTE Ltda. Após colhidos, os frutos foram transportados para o Laboratório da Embrapa Agroindústria Tropical (Fortaleza-CE), tratados por imersão com 300 ppm do fungicida Sportak, sendo avaliados no dia da colheita e após 21 dias de armazenamento refrigerado à temperatura de $13 \pm 1^{\circ} \mathrm{C}$ e $99 \%$ UR.

Cor da polpa e da casca - foram determinadas através de um Colorímetro Minolta, que expressa a cor em através da:três $p$ luminosidade (Larâmetros, que integralizados em um diagrama mostram a coloração do produto: $\left.\mathrm{L}^{*}, *\right)$, que oscila entre 0 (cores escuras ou opacas) e 100 (cores brancas ou de máximo brilho); cromaticidade ou pureza da cor $\left(C^{*}\right)$, cujos valores baixos representam cores impuras (acinzentadas) e os elevados às cores puras; ângulo de tonalidade ou

1 (Trabalho 043/2002). Recebido: 09/03/2002. Aceito para publicação: 26/09/2002.

Parte da dissertação de mestrado do $1^{\circ}$ autor apresentada à Universidade Federal do Ceará - UFC, Fortaleza-CE

2 Bolsista da FACEPE. Embrapa Semi-Árido, BR 428, KM 152, CP. 23, 56.300-970, Petrolina-PE. E-mail: plmorais@ hotmail.com. Fone: 873862 1711, ramal 177

3 Embrapa Agroindústria Tropical, CP 3761, 60.511-110, Fortaleza-CE. E-mail: heloisa@ cnpat.embrapa.br

4 Universidade Federal do Ceará, CP 12168, 60021-970, Fortaleza-CE. E-mail: licinio@ufc.br 
cor verdadeira $\left({ }^{\circ} \mathrm{Hue}\right)$, que varia entre $0^{\circ}$ e $360^{\circ}$, sendo que o ângulo 0 corresponde à cor vermelha, $90^{\circ}$ cor amarela, $180^{\circ}$ ou $-90^{\circ}$ cor verde, $270^{\circ}$ ou $-180^{\circ}$ cor azul, e passa de vermelho a negro em $360^{\circ}$.

Foram realizadas duas leituras nas áreas de cada cor característica da casca (partes verde e vermelha da casca). Na polpa, foram efetuadas uma leitura em cada face do fruto cortado. A avaliação da cor foi feita ainda,também através de comparação com a escala subjetiva de 1 a 5, proposta em GTZ (1992). Foram avaliadas, ainda, quantoà a perda de massa (\%); Firmeza a firmeza da polpa, - através de um texturômetro computadorizado, da marca Stable Micro Systems, modelo TA.XT2i, com probe de $6 \mathrm{~mm}$; Sólidos o teor de sólidos solúveis totais (SST), conforme - SST AOAC (1992); Acidez a acidez total titulável (ATT), -ATT segundo Instituto Adolfo Lutz (1985); o conteúdo de Aaçúcares solúveis totais (AST), segundo- AST Yemn \& Willis (1954); Teor o teor de amido, conforme AOAC (1992),) com algumas adaptações na quantidade de amostra inicial e no número de centrifugações; e Atividade a atividade respiratória, - determinada diariamente até atingir o pico climatérico, à temperatura média de $23^{\circ} \mathrm{C}$, através de um cromatógrafo CG, modelo DANI 8610, com detector de condutividade térmica e ionização de chama para análises de $\mathrm{CO}_{2}$ e de etileno, respectivamente. No entanto, a sensibilidade do equipamento não foi suficiente para detectar o etileno liberado pela manga.

$\mathrm{O}$ experimento foi conduzido em delineamento inteiramente casualizado, em esquema fatorial 5 × 2 (cinco estádios de maturação e dois tempos de armazenamento), com cinco repetições, com quatro cada.

\section{RESULTADOS E DISCUSSÃO}

Os resultados das medidas objetivas de cor $\left(\mathrm{L}^{*}, \mathrm{H}^{* \circ} \mathrm{Hue}, \mathrm{C}^{*}\right)$ da parte verde da casca do da fruto manga estão demonstrados nas Figuras 1(A, 1B, e1 C). Pode-se observar, nos gráficos, que Nno dia da colheita apenas os frutos colhidos no estádio E4 foram diferentes dos demais, e que, após o armazenamento, houve aumento de luminosidade $\left(\mathrm{L}^{*}\right)$, melhor definição da cor $\left(\mathrm{C}^{*}\right)$ e mudança de cor verde para amarela ( ${ }^{\circ}$ Hue ). Após este período, os frutos no estádio E4 apresentavam $\mathrm{L}^{*} \mathrm{e}$ $C^{*}$ mais elevados, não diferindo estatisticamente do EC para $L^{*}$, e do $\mathrm{EC}, \mathrm{E} 2 \mathrm{e} \mathrm{E} 3$ para $\mathrm{C}^{*} . \mathrm{O}^{\circ} \mathrm{Hue}$ dos frutos do estádio 4 também se destacou com valores inferiores aos demais, indicando que estes frutos estavam mais amarelos e com cor mais definida. Os frutos colhidos no estádio EC apresentaram características de cor intermediárias entre os estádios E4 e os demais.

$\mathrm{Na}$ porção vermelha da casca, pode-se observar para o parâmetro L* ( Figura 1D) que as diferenças de luminosidade ( $\left.L^{*}\right)$ entre os estádios e tempo de armazenamento foram muito pequenas (Figura 1D). Porém, os frutos colhidos no estádio E4 apresentaram $L^{*}$ e ${ }^{\circ} \mathrm{Hue}$ significativamente superior mais altos no dia da colheita . No dia da colheita os frutos no estádio 4 apresentaram maiores valores de $\mathrm{H}^{*} \mathrm{e}$ C* (Figuras 1E e 1F). Salles (1994) também observou maior evolução mais acentuada da cor da casca em frutos colhidos em estádios mais avançados de maturação (105 e 120 dias após a indução floral). Após o armazenamento, os valores mais altos de $\mathrm{C}^{*}$ foram superiores aos do dia da colheita comprovando que houve ummostraram melhor definição aumento na intensidade da cor. Os frutos colhidos nos estádios E2, E3 e EComercial não diferiram entre siforam semelhantes quanto ao desenvolvimento da cor vermelha na casca, tanto no que se refere à pureza da cor $\left(\mathrm{C}^{*}\right)$ quanto à definição da tonalidade vermelha ( ${ }^{\circ} \mathrm{Hue}$ semelhantes), enquanto os no estádio 1 apresentaram os menores valores de $\mathrm{C}^{*}$. Para o parâmetro $\mathrm{H}^{*}$ não houve diferença significativa entre os estádios..

A coloração externa dos frutos varia bastante acentuadamente com a intensidade e a quantidade de insolação que o fruto recebe. Portanto, a sua posição na planta e a estação do ano influenciam significativamente no desenvolvimento da cor, principalmente da cor vermelha, razão provável da diversivariabilidade ficação de resultados observada nos nos parâmetros de medida dessa variável.
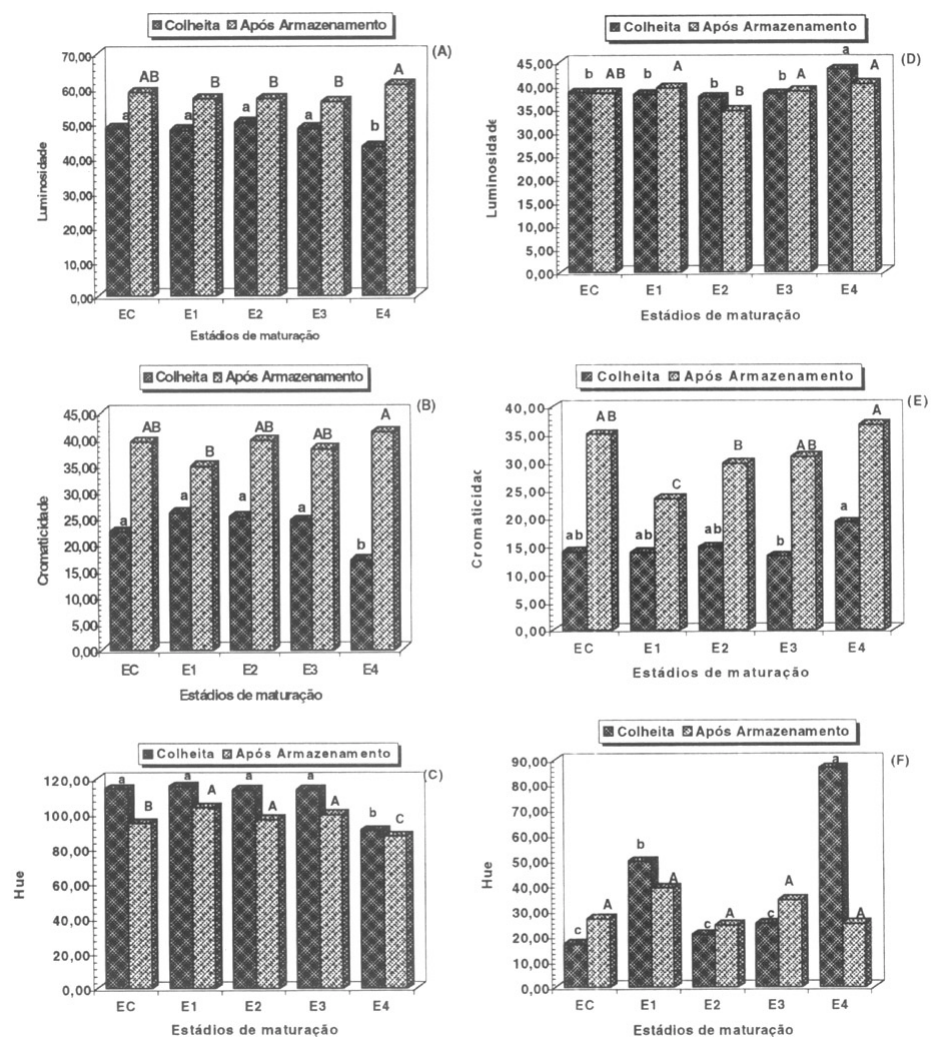

FIGURA 1 - Parâmetros de cor $\left(\mathrm{L}^{*}, \mathrm{C}^{*},{ }^{\circ} \mathrm{Hue}\right)$ na porção verde da casca $(\mathrm{A}, \mathrm{B}, \mathrm{C})$ e na porção vermelha $(\mathrm{D}, \mathrm{E}, \mathrm{F})$ de mangas 'Tommy Atkins' em cinco estádios de maturação, analisadas por ocasião da colheita e após 21 dias de armazenamento refrigerado $\left(13 \pm 1^{\circ} \mathrm{Ce} 99 \pm 1 \%\right.$ UR). Médias de um mesmo tempo de análise seguidas da mesma letra não diferem entre si ( $\mathrm{p}<0,05)$, pelo teste de Tukey. Letras minúsculas referemse ao dia da colheita e maiúsculas após o armazenamento.

Nas Figuras 2(A, 2B e 2C), pode-seestão representadas as alterações nas características de cor da polpa observar os valores de( $\mathrm{L}^{*}, \mathrm{H}^{* \circ} \mathrm{Hue} \mathrm{C}^{*}$ ) para cor da polpa. Ao contrário do que se observou na porção verde da casca, a luminosidade $\left(\mathrm{L}^{*}\right)$ diminuiu após o armazenamento dos frutos. Observa-se pelos resultados que as características de cor, quando consideradas em conjunto, foram semelhantes nos estádios EC, E2 e E3 Os após o armazenamento. frutos no estádio 4 apresentaram menores valores de $\mathrm{L}^{*} \mathrm{e} \mathrm{H}^{*}$ por ocasião da colheita e após o armazenamento, apesar de, no final do armazenamento, o valor de $L^{*}$ não ter apresentado diferença significativa dos frutos no estádio 3. Também, para o parâmetro $\mathrm{H}^{*}$ os frutos nos estádios $3 \mathrm{e}$ Comercial não diferiram daqueles no estádio 4. Os dados sugerem indicam que os frutos que nesses estádios apresentaram cor amarela mais alaranjada na polpa. Os frutos no estádio comercial não diferiram dos frutos no estádio 3 para o valor de $\mathrm{C}^{*}$ por ocasião da colheita, e após o armazenamento os frutos no estádio 4 foram os que apresentaram valores de $C^{*}$ superiores. Leon et al. (1997) observaram, para mangas da cultivar Manila, dados similares aos constatados neste trabalho para o parâmetro $\mathrm{H}^{* 0} \mathrm{Hue}$, por ocasião da colheita e após o armazenamento refrigerado $\left(12^{\circ} \mathrm{C}\right)$.

Os índices obtidos para cor da polpa, de acordo com a escala subjetiva, mostram que os frutos nos estádios E2 e E4 não diferiram estatisticamente entre si, assim como E3 e EC no dia da colheita; já após o armazenamento, os estádios EC, E3 e E4 foram estatisticamente iguaispor ocasião da colheita e (Figura 2D). Os frutos no estádio 4 foram os que apresentaram notas médias mais elevadas por ocasião da colheita e após o armazenamento, indicando uma maior intensidade na cor amarela da polpa. Porém, por ocasião da colheita os frutos no estádio 2 e ao final do período de armazenamento os frutos nos estádios 3 e Comercial não diferiram do estádio 4. Esses resultados estão compatíveis com os obtidos nos parâmetros de avaliação da cor através do 
colorímetro, da mesma forma que foi relatada por Medlicott et al. (1992), apesar deste de a escala ser um método subjetivo podendo apresentar maior possibilidadese portanto, mais sujeito a erros de avaliação de falhas. Medlicott et al. (1992) também observaram alta correlação entre o método de avaliação da cor da casca, através de escala subjetiva, e os parâmetros obtidos no colorímetro.

Filgueiras et al. (2000) relatam que atualmente se recomenda, como ponto de colheita para manga destinada à Europa e Canadá, um ponto de colheita com cor da polpa correspondente a nota entre 2 e 3 na escala. Portanto, os frutos nos estádios avaliados obtiveram notas compatíveis com as exigências do mercado para cor da polpa, com exceção das mangas colhidas no estádio E4, que já estavam apresentavam cor mais acentuada, com nota superior a 4,0.muito avançadas no que concerne à sua maturidade. Todavia, tem-se observado que esse indicador da maturação varia com a região de produção, pois mangas colhidas na região de Petrolina-PE, apresentam diferença na coloração da polpa em relação às das mangas produzidas na região Mossoró-Assu (RN), e no Estado do Piauí, tornado-se assim,sendo necessário o estabelecimento de uma escala própria para cada região de cultivo.

As perdas de peso durante o armazenamento não ultrapassaram ultrapassou a $4 \%$ (Figura 2E), sendoe os mais acentuada nos frutos no estádio comercial EC, seguido pelo E3, porémforam os que perderam mais. No entanto, a perda não foi suficiente para causar murchamento ou comprometer a aparência externa dos frutos. Evangelista (1999) constatou valores semelhantes, em torno de $3,5 \%$, para mangas cultivar Tommy Atkins com 21 dias de armazenamento refrigerado $\left(10 \pm 1^{\circ} \mathrm{Ce}\right.$ 80-90 \% U.R.). Evangelista et al. (1996) conseguiram reduzir essa perda de peso para aproximadamente $2,7 \%$, através do uso da refrigeração associada com cera.

As alterações na firmeza dos frutosda polpa em vários estádios de maturação, avaliados por ocasião da colheita e após 21 dias de armazenamento, está em vários estádios de maturação, avaliados por ocasião da colheita e após 21 dias de armazenamento, estão representadas na Figura 2F. Os Nos frutos colhidos nos estádios E2, E3 e EC, acomercial não apresentaram diferenças significativas para a firmeza média de polpa no dia da colheita foi semelhante, a qual está próxima à recomendada para o pontocomo índice de colheita mínimo desta cultivarpara a manga Tommy Atkins, que é de 129,36 N (Filgueiras et al., 2000). Durante oAo final do armazenamento, constatou-se acentuado amaciamento, não tendo os estádios E4, EC e E3 apresentado diferença significativa. armazenamento houve uma acentuada redução na firmeza, sendo os frutos no estádio 3 os mais semelhantes aos de colheita comercial, apesar dos frutos no estádio 2 não terem apresentado diferenças estatísticas significativas. As mangas no estádio 4 mostraram-se significativamente menos firmes que nos demais estádios, o que era de se esperar, pois a firmeza decresce com o avanço do estádio de maturação. Dados similares aos deste experimento para essa mesma cultivar foram observados por Evangelista (1999), no entanto, valores inferiores foram constatados por Rocha (2000), que observou uma variação de $96,14 \mathrm{~N}$ para $9,40 \mathrm{~N}$ por ocasião da colheita com o avanço da maturação.

A acidez apresentou pequenas oscilações, com uma tendência a diminuição diminuir com durante $\mathrm{o}$ armazenamento, para exceto nos frutos colhidos nos estádios 2, 3 e 4E1 (Figura 3A). Esse decréscimo pode serestá associado ao amadurecimentoà maturação, em decorrência do consumo dos ácidos no processo respiratório (Salles \& Tavares, 1999), ou nas rotas de conversão em componentes do aroma. Os frutos no estádio 3 foram os que apresentaram maiores níveis de acidez por ocasião da colheita, no entanto, os frutos nos estádios 1, 2 e comercial não diferiram do mesmo. Ao final do período de armazenamento os frutos no estádio 1 foram os que se destacaram com teores estatisticamente superiores. EssaA elevação de ATT acidez verificada nos no frutos, colhidos no estádio E1, após o armazenamento pode ser devidoé uma indicação de que os frutos foram colhidos imaturos. à imaturidade dos mesmos por ocasião da colheita. Os frutos no estádio
4 foram os que apresentaram menores teores de acidez após o armazenamento, apesar de não diferirem estatisticamente dos frutos nos estádios 2 e comercial.
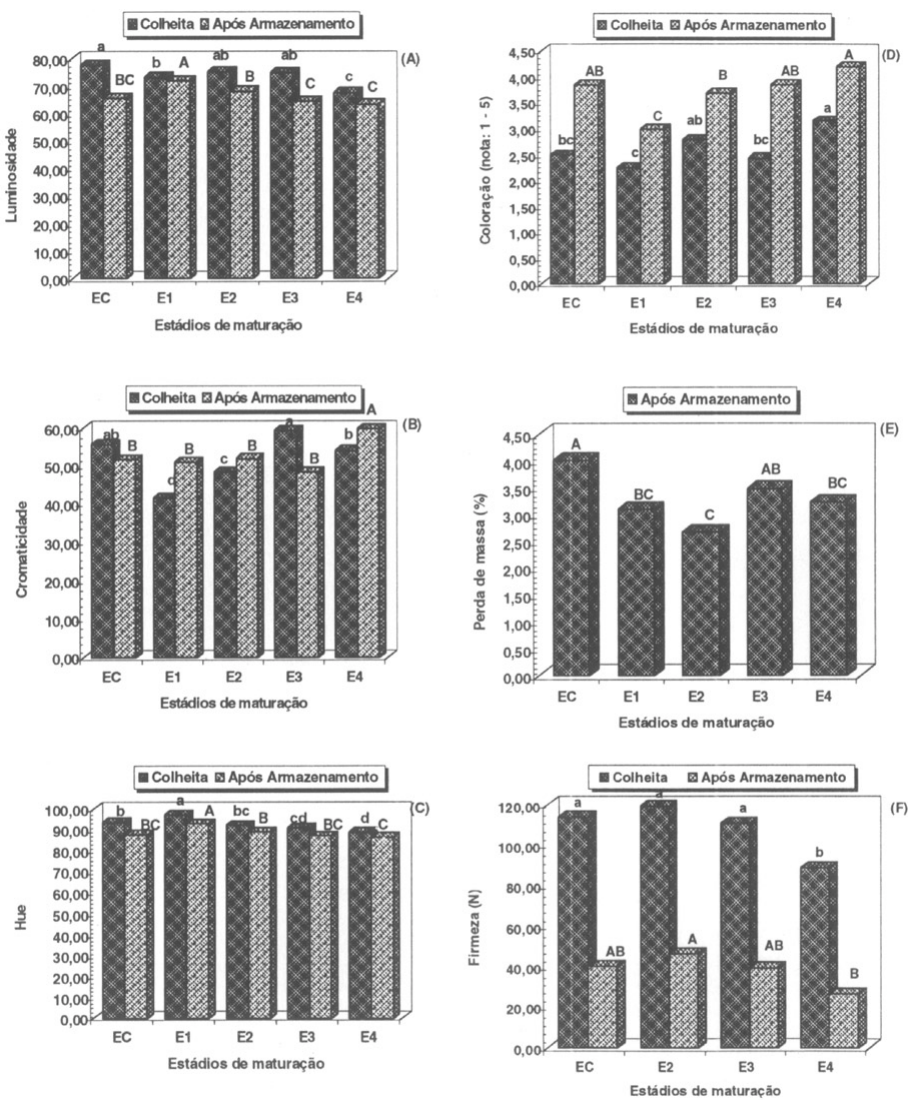

FIGURA 2 - Parâmetros de cor $\left(\mathrm{L}^{*}, \mathrm{C}^{*}, \mathrm{H}^{*}\right.$, nota 1-5) da polpa (A, B, C, $\mathrm{D})$, perda de massa (E) e firmeza (F) de mangas 'Tommy Atkins' em cinco estádios de maturação, analisadas por ocasião da colheita e após 21 dias de armazenamento refrigerado $\left(13 \pm 1^{\circ}\right.$ C.e $99 \pm 1 \%$ UR). Médias de um mesmo tempo de análise seguidas da mesma letra não diferem entre si $(\mathrm{p}<0,05)$, pelo teste de Tukey. Letras minúsculas referemse ao dia da colheita e maiúsculas após o armazenamento.

Esses dadosOs resultados obtidos para acidez dos frutos neste experimento estão dentro da faixa observada por Evangelista et al.(1996) e Salles \& Tavares (1999) na para a cultivar Tommy Atkins. No entanto, são considerados elevados quando comparados com a variação de 0,74 a $0,95 \%$ verificada relatada por Alves et al. (1998). Os frutos nos estádios 1, 4 e comercial atingiram valores compatíveis com as exigências dos padrões de qualidade do México, que requerem acidez de 1,22\% dos frutos, em estádio de maturidade mínima (Báez-Sañudo, 1997).

Houve Observa-se, na Figura 3B, um aumento considerável no conteúdo de SST na polpa das mangas do fruto após o período de armazenamento refrigerado a que foram submetidos, independentemente do estádio de maturação por ocasião da colheita. No dia da colheita os estádios E4 e EC não diferiram estatisticamente entre si,N mas, após o armazenamento, houve modificações significativas. Os teores de SST nos frutos colhidos nos estádios E3, E4 e EC foram muito próximos entre si, e mais elevados que nos estádios E2 e E1, sendo que, neste último, a evolução desta variável também indicou a imaturidade destes frutos. os frutos no estádio 4 apresentaram teores de SST superiores aos frutos nos estádios 1,2 e 3, que não apresentaram diferenças significativas entre si. Após o armazenamento os frutos nos estádios 3 , 4 e comercial atingiram valores estatisticamente semelhantes e superiores aos estádios 1 e 2 . Os frutos do estádio 1 foram os que apresentaram menor conteúdo de SST, constatando a influencia do estádio de maturação sob o seu conteúdo. Evangelista (1999), avaliando mangas da cultivar Tommy Atkins no estádio comercial, encontrou teores 
de sólidos solúveis totais similares aos obtidos nesta pesquisa. No entanto, por ocasião da colheita, esses teores mostraram-se inferiores aos verificados por Salles \& Tavares (1999), em vários estádios de maturação, mas após o armazenamento refrigerado atingiram valores semelhantes. Isso indica que ao longo do armazenamento as reservas de amido foram convertidas em açúcares solúveis.

O aumento nos teores de SST e a tendência à diminuição da ATT, em função do estádio de maturação e do período tempo de armazenamento, ocasionaram um acréscimo na relação SST/ATT após o armazenamento (Figura 3C). Os frutos nos estádios avaliados não apresentaram diferenças significativas por ocasião da colheita. Todavia, ao final do armazenamento, os frutos colhidos no estádio E4 destacaramse, apresentando a maior relação SST/ATT. Os frutos nos estádios E2, E3 e EC não apresentaram diferença significativa entre si, mas superaram os do estádio E1. A relação SST/ATT é um dos índices mais utilizados para determinar-se a maturação e a palatabilidade dos frutos. Chitarra \& Chitarra (1990) relatam que o equilíbrio entre ácidos orgânicos e açúcares é muito importante na avaliação do sabor dos frutos. Assim, no presente trabalho, os frutos colhidos nos estádios E2, E3 e ECcomercial não apresentaram diferenças significativas quanto ao sabor.

Na Figura 3D, observa-se de forma geral, queque os teores de AST aumentaram acentuadamente, em decorrência da hidrólise do amido (Figura 3E). As diferenças nos teores de AST entre os estádios de maturação foram mais acentuadas quando se compararam os estádios E3, E4 e EC com E1 e E2, tanto no dia da colheita quanto após o armazenamento. Os teores finais de amido foram semelhantes em todos os estádios, mesmo nas mangas maduras. houve um aumento nos açúcares solúveis totais com o armazenamento refrigerado. Por ocasião da colheita não observou-se diferença estatística para os açúcares solúveis totais, entre os frutos colhidos nos estádios 4, 3 e comercial e entre esses dois últimos e os estádios 1 e 2. Já após o armazenamento, os frutos no estádio 4 destacaram-se com maiores níveis de açucares solúveis totais, e nos estádios 3 e comercial foram semelhantes aos mesmos. Os valores médios de açúcares solúveis totais após o armazenamento concordam com os obtidos por Rocha (2000), o qual observou para essa cultivar um aumento com o avanço da maturação.

Houve umO decréscimo no teor de amido após o armazenamento foi expressivo, em torno de $88 \%$, dos níveis de amido após o período de armazenamentodemonstrando crescente conversão de amido em açúcares (Figura 3E). Maia et al. (1986) verificaram em mangas das cultivares variedades Rosa, Coité, Jasmim, Espada e Itamaracá um decréscimo semelhante ao observado neste experimento, mas porém os níveis teores iniciais de amido foram superiores. , principalmente, no estádio "de vez", onde os valores atingiram 9,36\%. No entanto, por ocasião da colheita os níveis de amido aproximaram-se aos observados por Rocha (2000) na cultivar Tommy Atkins. No dia da colheita os frutos nos estádios 1, 2 e 3 não diferiram do estádio comercial, o qual obteve maior conteúdo de amido.

Os frutos colhidos nos estádios E2, E3 e EComercial apresentaram um pico climatérico típico de produção de $\mathrm{CO}_{2}$ (Figura $3 \mathrm{~F}$ ), o que não ocorreu com os frutos no estádio E1, que estavam imaturos e nem com os no estádio E4, que foram colhidos após passado o pico climatérico (Figura 4).

As mangas no estádio E1 apresentaram taxa respiratória crescente, até 12 dias após a colheita, quando já apresentavam aparência comprometida por aspectos de murchamento e sintomas de ataque por fungos, causa provável da elevação na taxa respiratória. Mitcham \& McDonald (1992) constataramrelataram para esta mesma cultivarvariedade, no estádio imaturo e à temperatura de $20^{\circ} \mathrm{C}$, atividade respiratória em torno de $74,64 \mathrm{mg} \mathrm{CO} \mathrm{kg}^{-1} \cdot \mathrm{h}^{-1}$, bem muito inferior à atividade máxima constatada no presente trabalho, que foi de $156,04 \mathrm{mg}$ $\mathrm{CO}_{2} \cdot \mathrm{kg}^{-1} \cdot \mathrm{h}^{-1}$, diferença que, em grande parte, pode ser atribuída à elevada temperatura ambiente por ocasião das avaliações. Os frutos colhidos nodo estádio E2 atingiram o pico climatérico respiratório de 152,59 mg $\mathrm{CO}_{2} \cdot \mathrm{kg}^{-1} \cdot \mathrm{h}^{-1}$ decorridos 10 dias da após a colheita, enquanto os no estádio E3 foram um pouco mais adiantados, alcançando a taxa máxima respiratória $\left(104,11 \mathrm{mg} \mathrm{CO} \cdot \mathrm{kg}^{-1} \cdot \mathrm{h}^{-1}\right), 7$ dias após 170 horas da a colheita. As mangas do colhidas no estádio ECcomercial apresentaram pico semelhante ao estádio E3, tanto no tempo quanto nae taxa respiratória do pico climatérico muito semelhantes aos frutos no estádio 3. Já o estádio 4 teve inicio com $54,46 \mathrm{mg} \mathrm{CO} \mathrm{kg}^{-1} \cdot \mathrm{h}^{-1}$ de taxa respiratória e atingiu um mínimo de $13,49 \mathrm{mg} \mathrm{CO} \cdot \mathrm{kg}^{-1} \cdot \mathrm{h}^{-1}$ após 96 horas da colheita, sem sinal de pico.
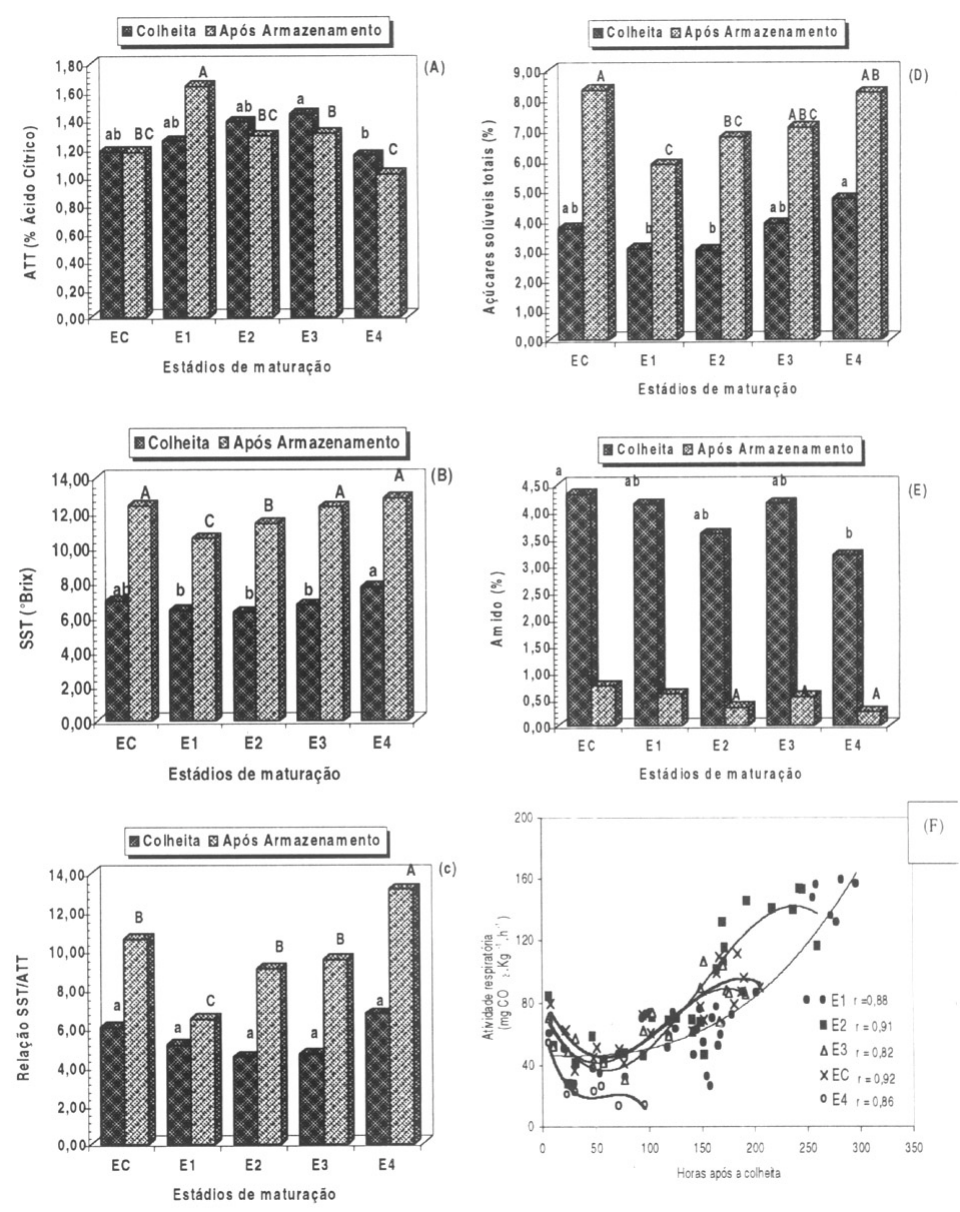

FIGURA 3 - Acidez total titulável (A), Sólidos solúveis totais (B), Relação SST/ATT (C) Açúcares solúveis totais (D), Amido (E) e Atividade respiratória (F) de mangas ‘Tommy Atkins' em cinco estádios de maturação, analisadas por ocasião da colheita e após 21 dias de armazenamento refrigerado (13 $\pm 1^{\circ} \mathrm{C}$ e $99 \pm 1 \%$ UR). Médias de um mesmo tempo de análise seguidas da mesma letra não diferem entre si $(\mathrm{p}<0,05)$, pelo teste de Tukey. Letras minúsculas referemse ao dia da colheita e maiúsculas após o armazenamento.

\section{CONCLUSÕES}

- Os frutos nos estádios com 89; 96; 103 DFP e o estádio comercial EC obtiveram apresentaram amadurecimento normal após 21 dias de armazenamento refrigerado. No entanto, os dono estádio com 89 DFP, apresentaram menoresos teores de SST foram mais baixos, e noos do estádio com 103 DFP já havia acontecido o pico climatérico, indicando que este estádio está muito avançado para atingir a vida útil necessária para o transporte e comercialização no mercado Europeu. Já asAs mangas nos estádios com 96 DFP e ECcomercial apresentaram-se muito semelhantes para todosna maioria dos índices de maturidade avaliados, e alcançaram o pico de qualidade, indicando que a colheita pode ser realizada nestes nesses estádios, sendo que aos 96 DFP pode ser considerado como mais um indicador do ponto de colheita de manga para a região de Mossoró.

- Os picos climatéricos ocorreram aos 10 dias após a colheita nas mangas do colhidas no estádio com 89 DFP estádio 2 e aos 7 dias nas dosnos estádios com 96 DFP e ECcomercial. As mangas colhidas nos dos 
estádios com 82 e 103 DFP não apresentaram pico climatérico.

\section{REFERÊNCIAS BIBLIOGRÁFICAS}

ALVES, R. M. V. ; SIGRIST, J. M. M.; PADULA, M. Atmosfera modificada em mangas 'Tommy Atkins'. Revista Brasileira de Fruticultura, Cruz das Almas, v.20, n.2, p.220-228, 1998.

ASSOCIATION OF OFFICIAL ANALYTICAL CHEMISTRY. Official methods of analysis of the association of official analytical chemistry. 11th. ed. Washington, 1992. 1115p.

BOTTON, C. G. de. Avaliação da qualidade de mangas transportadas por via marítima chegando na Europa pelo porto de Roterdã, Holanda. Revista Brasileira de Fruticultura, Cruz das Almas, v.14, n.2, p.121-125, 1992.

CHITARRA, M. I. F.; CHITARRA, A. B. Pós-colheita de frutos e hortaliças: fisiologia e manuseio. Lavras: FAEPE/ESAL, 1990. 543p.

EVANGELISTA, R. M.; CHITARRA, A. D.; GOLDONI, J. S.; CHITARRA, M. I. F. Efeito da aplicação de ceras comerciais na pós-colheita de manga (Mangifera indica L.) cv. Tommy Atkins. Revista Brasileira de Fruticultura, Cruz das Almas, v.18, n.1, p.105-113, 1996.

FAO. Dados agrícolas de FAOSTAT - producción - cultivos primários mango. Disponível em: www.url:http://apps.fao.org. Acesso em: 31 de julho de 2001.

FILGUEIRAS, H. A. C. et al. Colheita e manuseio pós-colheita. In: FILGUEIRAS,H.A.C. et al. Frutas do Brasil: manga. pós-colheita. Fortaleza: Embrapa Agroindústria Tropical. 2000. p.22-25.

GTZ - Deutsche Gesellschaft für Technische Zusammenarbeit Manual de exportacion frutas tropicales y hortalizas, Eschborn, 1992. 34p.

GUARINONI, A. Efecto del estado de madurez de los frutos a la cosecha sobre su conservación. In: CONGRESO IBEROAMERICANO DE TECNOLOGÍA POSTCOSECHA Y AGROEXPORTACIONES, 2 ., 2000, Bogotá, Colombia. Simposio: Control de fisiopatías en frutas durante el almacenamiento en frío, Bogotá, Colombia: Universidad Nacional de Colombia, 2000. v.1 p.29-38.

INSTITUTO ADOLFO LUTZ. Normas analíticas: métodos químicos e físicos para ánalise de alimentos. 2.ed. São Paulo; 1985. v.1.

LEITE, L. A. de S.; PESSOA, P. F. A.; ALBUQUERQUE, J. A.; SILVA, P.
C. G. O Agronegócios da manga no Nordeste. In: CASTRO, A. M. G. et al. Cadeias produtivas e sistemas naturais - prospecção tecnológica. Brasília: Embrapa-SPI, 1998. p.389-439.

LEON, D. M.; CRUZ, J. D.; PARKIN, K. L.; GARCIA, H. S. Effect of controlled atmospheres containing low $\mathrm{O}_{2}$ and high $\mathrm{CO}_{2}$ on chilling susceptibility of Manila mangoes. Acta Horticulturae, Leuven, Belgium, v. 455, p.635-642, 1997.

MAIA, G. A.; SILVA, M. F.; HOLANDA, L. F. F. de; MONTEIRO, J. C. S.; ORIAR, H. F.; FIGUEIREDO, R. W. de. Estudo da maturação de algumas variedades de manga (Mangifera indica L.). Revista Brasileira de Fruticultura, Cruz das Almas, v.8, n.2, p.67-74, 1986.

MEDLICOTT, A. P.; SEMPLE, A. J.; THOMPSON, A. J.; BLACKBOURNE, H. R.; THOMPSON, A. K. Measurement of colour changes in ripening bananas and mangoes by instrumental, chemical and visual assessments. Tropical Agriculture, Trinidad, v.69, n.2, p.161-166, Apr. 1992.

MITCHAM, E. J.; McDONALD, R. E. Cell wall modification during ripening of 'Keitt' and 'Tommy Atkins' mango fruit. Journal of the American Society for Horticultural Science, Alexandria, v.117, n.6, p.919-924, 1992

PIMENTEL, C. R. M.; ALVES, R. E.; FILGUEIRAS, H. A. C. Mercado internacional de manga: situação atual e perspectivas. In: PIMENTEL, C. R. M. et al. Frutas do Brasil: Manga. Pós-colheita. Fortaleza: Embrapa Agroindústria Tropical, 2000. p.9-13.

SALLES, J. R. de J.; TAVARES, J. C. Vida útil pós-colheita de manga (Mangifera indica L., cv. Tommy Atkins): Influência da temperatura e do estádio de maturação. Revista Brasileira de Fruticultura, Jaboticabal, v.21, n.2, p.171-176, ago. 1999.

SALLES, J. R. J. Vida útil pós-colheita de mangas cv. Tommy Atkins e Van Dyke: influência da temperatura e do estádio de maturação. 1994. 57f. Dissertação (Mestrado em Fitotecnia) - Escola Superior de Agricultura de Mossoró, Mossoró, 1994.

YEMN, E. W; WILLIS, A. J. The estimation of carbohydrate in plant extracts by anthrone. The Biochimical journal, London, v.57, p.504514,1954 . 